\title{
İÇSEL PARA TEORISII VE JOAN ROBINSON
}

$* * * *$

\section{ENDOGENOUS MONEY THEORY AND JOAN ROBINSON}

\author{
Dr. Utku BÜYÜKILGAZ \\ Bağımsız Araştırmacı \\ utkubuyukilgaz@marun.edu.tr \\ ORCID: 0000-0001-9980-9579
}

\begin{abstract}
$\ddot{O} \mathbf{z}$
Bu çalışmanın amacı, içsel para teorisi ve Joan Robinson'un bu teoriye yaptı̆̆ katkıların incelenmesidir. Joan Robinson'un para konusunda literatüre yaptı̆̆ı katkılarla ilgili görüşler çeşitlidir. Bu çalışmada hedeflenen, bu görüşlerin incelenmesi ve bu bağlamda konunun tartışılmasıdır. Bu amaç doğrultusunda, bu konuda daha önce yapılmış çalışmalar ve Robinson'un eserleri incelenmiştir. Varılan sonuç, Robinson'un Post Keynesyen para teorisinin gelişimine katkı yaptığ y yönündedir.
\end{abstract}

Anahtar Kelimeler: Post Keynesyen, İçsel Para, Uyumcu Yaklaşım, Yapısalcı Yaklaşım.

\begin{abstract}
The aim of this study is to analyze endogenous money theory and Joan Robinson's contribution. The opinions are divided about Joan Robinson's contribution to monetary issues. The purpose of this study is to examine this views and discuss the subject. For this purpose, previous studies and Robinson's works are examined. As a conclusion, Robinson made a contribution to evolution of Post-Keynesian monetary theory.
\end{abstract}

Keywords: Post-Keynesian, Endogenous Money, Accomodationist Approach, Structuralist Approach 


\section{GİRIŞ}

Joan Robinson, iktisat bilimine değerli katkılarda bulunmuş, modern iktisat teorisinin gelişiminde önemli rol oynamış isimlerden biridir. Ancak genellikle katkı sağladığı konular sayılırken, eksik rekabet, büyüme ve sermeye birikimi başlıkları öne çıkarılmaktadır. Robinson'un paraya dair görüşleri, dönemin diğer önemli iktisatçılarının gölgesinde kalmış gözükmektedir.

İçsel para teorisinin ortaya çıkışı genellikle, 1959 tarihinde kurulan Radcliffe Komitesinin üyelerinden olan Nicholas Kaldor'un görüşlerine ve Hyman Minsky'nin 1957 tarihli (Minsky, 1957a; Minsky, 1957b) çalışmalarına dayandırılmaktadır. Daha sonra yapılan bazı çalışmalar ise (Rochon, 2001a; Gnos ve Rochon, 2003; Vernengo ve Rochon, 2001), Robinson'un içsel para teorisine daha erken dönemde, oldukça önemli katkılarda bulunduğunu iddia etmektedir.

Robinson'un para teorisine olan katkılarıyla ilgili iki farklı görüş bulunmaktadır. Bunlardan ilki, Robinson'un paraya ilgi duymadığını ve çalışmalarının dışında bıraktığını ileri sürerken, bir diğeri onu içsel para teorisini kurucusu saymaktadır. Bu çalışmada, bu iki karşıt görüşün ortaya koyduğu fikirler değerlendirilmekte ve Joan Robinson'un para teorisine yağtığı katkı tartışılmaktadır. Bu çalışma iki bölümden oluşmakta olup, ilk bölümde içsel para teorisinin gelişimi, Post Keynesyenlerin teoriye katkıları ile uyumcu ve yapısal yaklaşım ayrımına yer verilecek, ikinci bölümde ise Joan Robinson'un paraya dair görüşleri ve para teorisine katkıları ele alınacaktır.

\section{POST KEYNESYENLER VE İÇSEL PARA}

\section{1. İçsel Paranın Tanımı}

Post Keynesyen iktisatın parasal analizlerinin temelini içsel para teorisi oluşturmaktadır. İçsel para teorisi, para arzının merkez bankalarınca belirlenemeyeceğini, kredi talebi ve tüketici tercihleri tarafından belirlendiğini ileri sürmektedir. Post Keynesyenlere göre krediler, mevduatları yaratmaktadır. Kredi ve mevduatlar arasındaki nedensellik ilişkisinin ters yönlü olduğunu ileri sürdüğünden, içsel para teorisine göre bankalar kredi genişlemesi için mevduat stokuna ihtiyaç duymamaktadırlar. Bu bağlamda kredi ve dolayısıyla para arzının yaratılma süreci, herhangi altın ya da para rezervine bağımlı olmaksızın, kendiliğinden gerçekleşmektedir (Lavoie, 2006a:57).

Rochon, içsel para teorisinin genel önermelerini şu şekilde özetlemektedir;

- Miktar teorisindeki para ve gelir arasındaki nedensellik ilişkisi, içsel para teorisinde tersine işlemektedir. Nedensellik firmaların beklenen gelirinden, kredi talebine ve paradan efektif gelire doğrudur.

- Rezervler, mevduatlar ve krediler arasındaki nedensellik de tersine işlemektedir. Rezervler içseldir ve krediler üzerinde herhangi bir etkisi yoktur. Bu önerme para çarpanı modelinin reddi anlamina gelmektedir.

- Tasarruf ve yatırım arasındaki nedensellik ilişkisi, içsel para teorisinde ters yönlüdür. Firmalar herhangi bir tasarruf yapmadan önce üretimi finanse etmelidir.

- Faiz oranları dışsaldır, piyasa mekanizmasının faizlerin belirlenmesi üzerinde bir etkisi yoktur.

- Para arzı, talep ve kredi tabanlıdır. Kredi talebi dışsaldır ve ticari bankaların kararları tarafından yön verilmektedir (Rochon, 2001a:294).

\section{2 İçsel Para Teorisinin Ortaya Çıkışı}

İçsel para teorisinin ortaya çıkışı XIX. yüzyılın ortalarına kadar dayanmaktadır. $\mathrm{Bu}$ dönemde Bankacilık Okulu (The Banking School) ve Nakit Okulu (The Currency School) arasinda, monetaristler ve Post Keynesyenlerin arasındakine benzer fikir ayrılıkları bulunmaktaydı. 1830 ve 1840'lı yıllar boyunca devam eden tartışmaların merkezinde; para ve harcamalar arasındaki ilişki, Bank of England'ın paranın miktarını kontrol edebilme yetisi, paranın miktarı ile İngiltere'nin dış dengesi arasındaki ilişki bulunmaktaydı. Post Keynesyenler gibi paranın kaynağının kredi 
mekanizması olduğunu savunan Bankacılık Okulunun bu dönemde öne çıkan isimleri Thomas Tooke ve John Fullarton olmuştur (Wray, 1990:100-110).

1930 yılına gelindiğinde Keynes, “A Treatise on Money" adlı kitabını yayınlamış ve bu eserde paranın yaratım sürecinin içsel olduğunu kabul eder bir tavır ortaya koymuştur. Ancak 1936'ya geldiğimizde "Genel Teori" adlı ünlü eserini yayınlayan Keynes, burada paranın miktarını belirleyenin parasal otoriteler olduğunu söyleyerek, daha önceki söylemlerini değiştirmiş ve para arzının dışsal olduğunu kabul etmiş̧tir. Bu değişimin nedeni, zaten yeterince tartışma yaratması beklenen eserine, oldukça ihtilaflı bir konuyu daha eklemekten kaçınması olarak yorumlanmaktadır (Foster, 1986:955). Keynes sonrası dönemde ise, dışsal para arzı ana akım iktisat teorisinin bir parçası haline gelmişs, ISLM analiziyle birleştirilmiş ve sonrasında monetaristler tarafından da kabul görmüştür (Wray, 1990:131).

Modern anlamda içsel para teorisinin ortaya çıkış1 1950'lerin sonlarına denk gelmektedir. 1959 Britanya'da toplanan Radcliffe Komitesi, içsel para anlayışının gelişimi için bir dönüm noktası olarak kabul edilmektedir. II. Dünya savaşı sonrasında İngiltere'deki yüksek likidite miktarı, yetkilileri aşırı harcama ve enflasyona yol açabileceği yönünde endişelere sevk etmiştir. Bunun bir sonucu olarak, daraltıcı para politikaları uygulanarak likidite miktarının kontrol altına alınıp alınamayacağının araştırılması için bu komite kurulmuştur (Özgür, 2008:56). Komite bu konuyla ilgili olarak, parasal aktivitelerin amacının mal ve hizmetlere olan toplam talebi düzenlemek olduğunu ve bu amaca ulaşmak için seçilecek yolun emisyon ve banka mevduatlarının kontrolü olmadığını ortaya koymuştur. Komite, para arzı ile toplam talep arasındaki bağlantının belirsiz oluşunu, paranın dolaşım hızının limitlendirilmesinin imkansız olmasına bağlayan görüşe de karşı çıkmaktadır. Paranın dolaşım hızının tarihsel veriler 1şı̆̆ında herhangi bir limiti olmadığına vurgu yapmışlardır. Paranın miktar teorisi de dolaşım hızı üzerinden eleştirilmiş ve dolaşım hızı herhangi nedensel bir önemi olmayan istatistiksel bir konsept olarak nitelendirilmiştir (Kaldor, 1960:14-19).

Radcliffe Komitesinde üye olarak yer alan ve görüşleriyle yayınlanan rapora yön veren isimlerden olan Nicholas Kaldor, 1970 yılında yayınladığı çalışmasında, para arzının monetaristler tarafından ileri sürüldüğ̈̈ gibi dışsal değil, içsel olduğunu iddia etmiştir (Kaldor, 1970:9). Bu tarihten sonra Kaldor, paranın dolaşım hızı üzerinde yoğunlaşan tartışmaları başka bir düzleme taşımış, para arzındaki artışın kredi harcamalarında yaşanan bir artışın sonucu olduğu fikrini ortaya atmıştır. Kaldor, para arzının kredi talebi tarafından belirlendiğini, harcamalar ile para arzı arasındaki stabil ilişkinin de bunun kanıtı olduğunu savunmaktadır (Wray, 1990:132-133). Kaldor, para arzının kredi talebi tarafından içsel olarak belirlenirken, faiz oranının ise dışsal olarak merkez bankası tarafından belirlendiğini kabul etmektedir. Bu ifadenin matematiksel karşılığını, para arzı eğrisini yatay ve faiz oranının bir fonksiyonu olarak para talebi eğrisini ise negatif eğimli konumlandırarak göstermektedir. Para arzının yatay oluşu Kaldor ve sonrasında Moore gibi iktisatçıların geliştirdiği bu yaklaşımın yataycı (horizontalist) olarak adlandırılmasına yol açmıştır. Kaldor içsel para yaklaşımının gelişimine önemli katkılarda bulunmuş, ancak neden toplam para arzı içsel kabul edilmeli sorusuna mikro ekonomik açıdan cevap verecek, ticari bankacılık üzerinden sistematik bir model kurmadığı için eleştirilmiştir (Moore, 1991a:235-239).

Yine aynı dönemde içsel para teorisine katkı veren bir diğer isim, Amerikalı iktisatçı Hyman Minsky olmuştur. Minsky, 1957 yllından itibaren ortaya koyduğu çalışmalarla içsel para teorisine yapısalcı (structuralist) bir yaklaşım getirmiştir. Minsky, paranın içsel yaratım mekanizmasını, finansal kurumların gerçekleştirdiği inovasyonlara bağlamaktadır. $\mathrm{Bu}$ inovasyonlar banka rezervlerindeki artışlardan bağımsız olarak ticari aktivitelerin genişletilmesine olanak sağlamaktadır. Minsky, inovasyonlarla sıkı para politikasını da ilişkilendirmektedir. Ticari genişlemenin enflasyonu arttıracağını düşünen parasal otorite, sıkı para politikası uygulayacak, bu da faiz oranlarının artışına neden olacaktır. Yükselen faiz oranlarından fayda sağlamak isteyen finansal kurumlar, kredi talebini karşılamak için yeni yollar bulacaktır. Merkez bankasının ekonomiye koyduğu kısıtlar, faizlerde artışa neden olacak, bu da paranın dolaşım hızını arttıracak olan inovasyonları arttıracaktır. Minsky'ye göre, artan dolaşım hızını dengelemek için toplam rezervlerde azalmayı sağlayacak politikalar dışında kalan, parasal büyüklükleri kısıtlamaya yönelik para politikaları etkin olamayacaktır (Wray, 1990:135). Sık1 para politikalarının uygulayarak parasal genişlemenin önüne geçmenin yolu, faiz oranlarını 
girişimcilerin geleceğe yönelik kar beklentilerini ortadan kaldıracak seviyeye çıkarmaktır. Bu politika firmaların geleceğe yönelik harcamalarını olumsuz etkileyerek, parasal genişlemeyi yavaşlatabilmektedir (Özgür, 2008:58).

\section{3. İçsel Para Teorisinin İki Farklı Yorumu: Uyumcu ve Yapısal Yaklaşım}

Post Keynesyenler, içsel parayla ilgili görüşleri bağlamında, kendi içlerinde ayrışmaktadırlar. Post Keynesyen literatür gelişirken, para arzının içselliği ile ilgili iki ayrı yaklaşım ortaya çıkmıştır. İki yaklaşım da para arzının kredi talebi tarafından belirlendiğini, bankaların önce kredi genişlemesine gittiğini, bu sayede yeni mevduatlar yarattığını, daha sonra ise ortaya çıkan rezerv ihtiyaçları için kaynak aradığını kabul etmektedir. Ayrıldıkları nokta ise rezervler için aranan kaynakların nereden ve nasıl bulunacağı ile ilgilidir. İlk yaklaşım ticari bankaların ve diğer finansal aracıların rezerv kıtlığı çektiği durumlarda, merkez bankaları bu ihtiyaçlara uyum sağlaması gerektiğini, aksi halde finansal yapının ve hatta tüm ekonominin risk altında kalacağını ileri sürmektedir. Merkez bankalarının bu durumda tercih edebileceği iki yol vardır. Bunlardan ilki, açık piyasa işlemleri yoluyla ödünç alınmamış rezerv miktarının arttırılması, ikincisi ise bankaların ellerindeki rezervleri reeskont ettirmelerini sağlamaktır. Merkez bankaları, reeskont kredisi taleplerini karşılamakla yükümlü olduklarından, bankaların rezerv ihtiyaçlarına herhangi bir kısıt olmadan uyum sağlamalıdır. $\mathrm{Bu}$ yaklaşıma uyumcu (accommodative) para arzı içselliği adı verilmektedir (Pollin, 1991:367). ${ }^{1} \mathrm{Bu}$ yaklaşıma katkı veren isimler arasında, Kaldor, Moore, Weintraub, Lavoie, Rochon, Rogers ve Smithin sayılabilir (Fontana, 2003:294).

İkinci yaklaşım ise, merkez bankalarının ödünç verilmemiş rezervlerdeki büyümeyi, açık piyasa işlemelerine kısıtlar koyarak kontrol altında tutmaya çalıştı̆ııı kabul etmektedir. Bu görüşe göre, reeskont kredileri, açık piyasa işlemlerine bir alternatif oluşturmamaktadır. Bu yaklaşım, merkez bankaları ödünç alınmamış rezervlerin büyümesini kısıtlama yoluna gittiğinde, bankaların inovatif borç yönetimi yoluyla gerekli rezervleri edinebildiğini ileri sürmektedir. Bu yaklaşıma yapısal (structural) para arzı içselliği adı verilmektedir. (Pollin,1991:368) Chick, Minsky, Rousseas, Dow, Howells, Palley, Sawyer, Wray gibi isimler yapısal para arzı içselliği yaklaşımına katkı sağlamışlardır. (Fontana, 2003:297)

Yapısal yaklaşım, uyumcu yaklaşımı bazı yönlerden eleştirmektedir. Bu noktalardan biri, merkez bankalarının her zaman rezerv ihtiyaçlarına uyum sağlayamayacağıdır. Bazı durumlarda merkez bankaları rezerv ihtiyaçlarına kısmen uyum sağlayabilir, bunun sonucu olarak da borç yönetimi gibi yapısal değişiklikler ortaya çıkacaktır. Eleştiriye uğrayan bir diğer husus, uyumcu yaklaşımın kredi tayınlamasını göz ardı etmesidir. Merkez bankaları rezerv taleplerine tam olarak uyum sağlasa bile, kredi arzının her zaman yatay olmayabileceği, uyumcu yaklaşımın eleştiriye maruz kaldığı bir diğer konudur. Yataycılar, arz ve talepteki değişimlerin kısa ve uzun dönem faiz oranlarında meydana getireceği değişiklikleri göz ardı etmektedir. Bu aynı zamanda likidite tercihinin de göz ardı edildiği anlamına gelmektedir. Yapısalcılar, içsel paranın sadece kapalı ekonomi üzerinden geliştirilmiş bir teori olmasına da vurgu yapmaktadırlar (Lavoie, 2006b:17).

Uyumcu (yatayc1) yaklaşımın gelişiminde önemli yeri olan isimlerden Basil Moore'a göre merkez bankalarının asli görevi, yetkili merci olarak finansal sistemin likidite ihtiyacını her daim karşılayabilecek durumda olmaktır. Moore, Kaldor gibi para arzının yatay olduğunu kabul etmektedir. Para arzı yatay olduğu müddetçe, merkez bankalarının para arzına, sadece kısa dönem faiz oranları değiştirerek dolaylı yoldan etki edebileceklerini ileri sürmektedir (Moore, 1984:106-107).

Yapısal yaklaşımın temsilcilerinden Palley, uyumcu yaklaşımın, politika yapıcılar ve bankaların aldıkları kararlar arasındaki bağlantıyı ve bunların finansal piyasalar ile para politikaları üzerinde oluşturacakları etkileri incelemekte yetersiz kaldığını savunmaktadır. Palley, uyumcu yaklaşımın

\footnotetext{
${ }^{1}$ Basil Moore, merkez bankalarının tutumlarını uyumcu ya da uyumcu olmayan şeklinde tanımlanın, fayda sağlamaktan çok yanlış yönlendirmeye yol açtığına vurgu yapmaktadır. Moore, terminolojik olarak "accommodative" yerine "horizontalist" teriminin kullanımın daha uygun bulmaktadır. (Moore, 1988:18) Bu görüşe katılan bir diğer isim için bkz. (Lavoie, 2006b:17)
} 
ortaya koyduğu, merkez bankalarının uygulayabilecekleri tek politikanın faiz oranlarını kontrol etmek olduğu tezini kabul etmemektedir. Kredi talebindeki artış sonrası bankalar kredi genişlemesine gider, bunun sonucu olarak artan mevduat stoku rezerv talebini arttırır, parasal otorite de bu artan talebe tam olarak uyum sağlayarak faiz oranlarını değiştirir. Palley, uyumcu yaklaşımın para arzının yaratım sürecini bu noktada kestiğini, ama sürecin bu noktadan sonra da devam edebileceğini ileri sürmektedir. Ona göre, banka kredileri ve buna bağlı olarak rezerv talebi arttıkça, merkez bankası federal fon oranını arttırarak, bankaların ihtiyaçlarına kısmen uyum sağlayabilir. Bu uygulamaya reeskont oranlarının arttırılması, reeskont kredilerine sınırlama getirilmesi, rezerv artışının önüne geçebilmek için piyasadaki ödünç alınmamış rezervlerin toplanması gibi bazı ek tedbirler de eşlik edebilmektedir. Bankaların böylesi bir senaryoda yapacakları hamle, fon teminin en ucuz yolu olan varlık ve borç yönetimi olacaktır (Palley, 1996:585-590).

Moore yapısalcılardan gelen bu eleştirilere, parasal otoritenin faiz oranlarını sadece mevcut piyasa dönemi için belirlediğini, bu dönem boyunca para arzının yatay olarak kabul edileceği şeklinde karşılık vermektedir. Rezerv arzını pozitif eğimli gösteren yapısalcı yaklaşımın geçersiz olduğunu öne sürmektedir. Rezerv arzı fonksiyonunun eğiminin merkez bankalarının uyum seviyesine bağlı olduğunu, ancak kısa dönem oranlar tarihsel olarak incelendiğinde, faiz oranının her zaman banka kredileriyle eşit oranda artmayabileceğine vurgu yapmaktadır. Ayrıca yapısalcıların ortaya koyduğu, parasal otoritenin faiz oranlarını değiştirmenin yanında, rezerv miktarındaki artışın önüne geçmek için başka ek önlemler de alabileceği fikrine karşı çıkmaktadır. Moore'a göre, merkez bankaları açık piyasa işlemleri yoluyla ödünç alınmamış rezerv miktarını arttırıp azaltabilmektedir. Ancak bankaların rezerv ihtiyacı, bir önceki kredi genişlemesi ve mevduat yaratımı süreci tarafından belirlendiğinden, ödünç alınmamış rezervlerde meydana gelecek herhangi bir değişim, serbest rezervlerde de aynı oranda bir değişime yol açacaktır. Bunun sonucunda da kısa dönem faiz oranlarında değişim gözlenecektir. Merkez bankası rezervleri arttırıp azaltarak kısa dönem faiz oranı hedeflerini tutturmaya çalışacaktır. Para arzı ve parasal taban böylelikle tamamen içsel olmaktadır (Moore, 1998:175-176).

Uyumcu ve yapısal yaklaşımın uzlaşamadığı konuların başında, para arzı eğrisinin yatay olması gelmektedir. Lavoie yataycı anlayışı, neoklasik olmayan parasal üretim ekonomisi ortaya koymak için kullanılabilecek bir yöntem olarak tanımlamaktadır. Yapısal yaklaşımın önerdiği gibi para arzı eğrisi pozitif eğimli olduğunda, içsel para IS-LM modeline, modelde herhangi bir değişikliğe yol açmadan uygulanabilmektedir. Lavoie, bu tür bir içsel para anlayışını kabul etmeleri halinde, Post Keynesyenler ile neoklasikler arasında herhangi bir fark kalmayacağını ifade etmektedir (Lavoie, 1996:276).

Yatay para arzının yarattığı tartışmalardan biri de, likidite tercihinin göz ardı edilmesidir. Yapısalcılar, yataycıların kredi tabanlı para arzı görüşünün, likidite tercihi teorisinin ortaya koyduğu bireylerin belirli saiklerle para talebinde bulunabileceği görüşüyle çelişmesini eleştirmektedir. Moore, mevduatların kredilerce yaratıldığını ve mevduatlarda yaşanacak bir düşüşün, borçluların kredileri geri ödemesi yoluyla oluşacağını kabul etmektedir. Piyasada oluşan mevduat talebinin, arz edilen mevduat miktarına bağlı olduğunu, bağımsız bir para talebi fonksiyonu bulunmadığını ileri sürmektedir (Moore,1991b:127). Lavoie ise bu tartışmalarla ilgili, yataycıllğın likidite tercihi teorisiyle uyumlu olabileceğini, likidite tercihi, finansal kırılganlık gibi konseptlerin yataycı içsel para yaklaşımı dahilinde ele alınabileceğini iddia etmektedir (Lavoie, 1996:276). 
Grafik 1. Likidite Tercihi ve Yataycı Yaklaşım
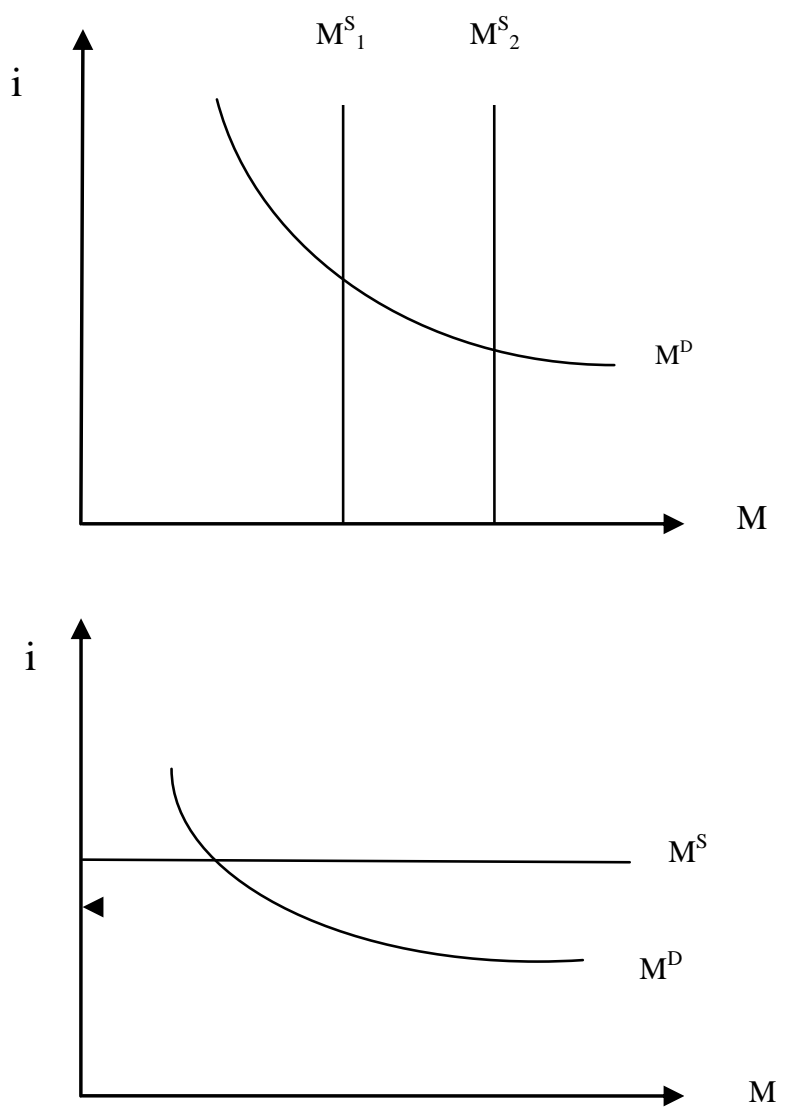

Kaynak: Chick ve Dow,2006:590

Grafiklerde likidite tercihi teorisi ve yataycı yaklaşımın, para arz ve talebi eğrileri gösterilmektedir. İlk grafikte para talebi eğrisi, likidite tercihini temsil etmektedir. Bu grafikte para arzı verilidir ve faiz oranlarındaki değişimden etkilenmemektedir. Para arzı, parasal otoritelerce belirlenmektedir. Yataycı yaklaşımı gösteren ikinci grafikte ise, ilkinin aksine para arzı, kredi tabanlı ve talep tarafından belirlenir bir özelliktedir. Yani bankaların kredi arzı miktarını, borç alanların kredi talebi belirlemektedir. Kredi arzı tam esnektir, bu da kredi arzının sadece mevduat üretiminden sorumlu olduğu anlamına gelmektedir. Bankalar, kredi oranlarındaki artışı parasal otoritenin faiz oranlarındaki artışa göre belirlerler. Bu nedenle para arzı, parasal otoritenin belirlediği faiz düzeyinden yatay olarak çizilmektedir. Bu yaklaşımın yataycı olarak adlandırılmasının nedeni budur (Chick ve Dow, 2002:589).

Yapısalcı yaklaşım, likidite tercihinin bankalar tarafından sağlanan kredi düzeyi üzerinde direkt etkisi olduğunu savunmaktadır. Sadece bankacılık sektörünün değil, firmalar ve hane halklarının da kredi talebi ve dolayısıyla kredi yaratım sürecinde katkısı olduğunu ileri sürmektedirler. Oysa uyumcu yaklaşım likidite tercihini modelinin dışında bıraktığı için, onlar için kredi talebi ve para talebi aynı anlama gelmektedir. Yapısalcılar para ile kredinin eş tutulmasına karşıdırlar. Çünkü kredi ile paranın aynı şey olduğunu ileri sürmek, parayı elinde tutanlarla krediyi alan kişilerin aynı olduğunu varsaymak anlamına gelmektedir. Kredinin amac1, oluşan mevduatı mal, hizmet veya varlık karşılığında değiş tokuş etmek olduğundan böylesi bir varsayımı kabul etmenin hata olacağını iddia etmektedirler (Dow, 2006:36-44).

$\mathrm{Bu}$ konuya farklı bir açıdan yaklaşan Arestis ve Howells, stok ve akım değişken kavramları üzerinden, uyumcuların yatay para arzı eğrisinin geçerliliğini sorgulamaktadırlar. Genel olarak para 
stok, krediler ise akım değişken olarak ele alınmaktadır. Para arzının yatay oluşunun, stok değişkenler için hazırlanmış bir grafikte akım değişkenlerin de yer bulmasına neden olduğunu ve bunun yaklaşımın yapısal bir sorunu olduğunu ileri sürmektedirler (Arestis \& Howells, 1996:540). Rochon bu eleştirilere, Post Keynesyenlerin, arz-talep analizinin kredi ve para üzerine uygulanmasından doğan bu tür teorik kısıtlamaların ötesine geçmeleri gerektiğini söyleyerek karşılık vermektedir (Rochon, 2001b:33).

Ekonomik aktörlerin beklentileri üzerinden yapılan varsayımlar, yapısalcılar ve yataycılar arasında fikir ayrılığına neden olmaktadır. Yataycılar, bütün aktörlerin beklentilerinin, para arzı yaratım süreci içinde verili olduğu varsayımı üzerine kurulu bir analiz yapmaktadırlar. Bu varsayım sürekli değişen beklentiler üzerinden sabit fonksiyonel bir ilişki tanımlamayı çok zor hale getirmektedir. Öte yandan yapısalcılar ise, ekonomik aktörlerin beklentilerinin gerçekleşen değişimlere göre yön değiştirebileceğini hesaba katarak bir teorik çerçeve çizmektedirler. Yapısalcılar bu sayede, para politikasındaki değişikler, bankaların likidite tercihleri, kredi-mevduat ilişkisi gibi konularda ortaya çıkabilecek tartışmalarda, uyumculara kıyasla görüşlerini daha sağlam zemine oturtabildiklerini savunmaktadırlar (Fontana, 2011:130).

Gelinen noktada yapısalcı ve uyumcular arasındaki tartışmalar devam ediyor olsa da, iki görüşün birbirine yaklaştı̆̆ hususlar bulunmaktadır. Yapısalcılar zaman zaman merkez bankalarının faiz oranlarını belirleyebileceğini işaret ederken, uyumcular da bankaların rezerv ihtiyaçlarına merkez bankalarının her zaman tam uyum sağlayamayabileceğini kabul etmektedirler. Bütüncül bir içsel para teorisi ortaya koymak için iki yaklaşımın birlikte ele alınması gerektiği gayet açıktır. Yaklaşımlar arasındaki sınırların silikleşmesi de bu amaca hizmet etmektedir.

\section{3. İÇSEL PARA VE PARA POLITIKKALARI}

Paranın içsel olduğu görüşünü paylaşan iki ana düşünce okulu; yeni uzlaşı ${ }^{2}$ ve Keynesyenlerdir. Yeni uzlaşı, paranın içsel yaratımını, para talebine bağlı olarak para stoğundaki oluşan artık kısma bağlamaktadır. Keynesyen analiz ise buna ek olarak bankaların kredi yoluyla içsel para yaratım sürecine dahil olduklarını ileri sürmektedir. Her iki görüş de para politikalarını faiz politikasına indirgemektedir. Yeni uzlaşı, para politkasının talep enflasyonunu kontrol etme rolüne odaklanmaktadır. Bu görüşe göre, uzun dönemde enflasyon nominal GSYIHH olarak her daim var olacaktır. Ancak arz şokları gelip geçicidir. Yeni uzlaşı, enflasyonun faiz politakaları yoluyla kontrol edilebileceğine, faiz oranlarının talebi, talebin de enflasyonu etkileyiceğine vurgu yapmaktadır (Arestis \& Sawyer, 2006:847-848). Yeni uzlaşı, fiyat istikrarının sağlanmasını, faiz oranları üzerinden toplam talebin dengelenmesine bağlamaktadır. Ancak bu politika yaklaşımı, çekirdek enflasyonun talep kaynaklı olduğu varsayımına dayanmaktadır. Ancak enflasyon aynı zamanda maliyet kaynaklı bir olgudur ve merkez bankasının kısa dönem faiz oranlarında yapacağı değişiklik üretim açığını her iki yönden de etkileyecektir (Fontana \& Palacio-Vera, 2003:514).

Post Keynesyen para politikasının temelini de faiz politikaları oluşturmaktadır. Ancak artık birçok ana akım iktisatçı da bu yaklaşımı desteklemekte ve merkez bankalarının çoğu bu politikaları uygulamaya koymaktadır. Ana akım iktisat, para politikası kararlarını IS-LM modeline dayandırmaktadır. Bu modele göre, LM'nin IS'den daha değişken olduğu durumlarda faiz politikası uygulanmalıdır. Buradaki amaç, reel sektörü finansal sektör şoklarından korumaktır. Yani ana akım iktisatın para politikası aracı olarak para arzı yerine faizleri seçmesinin ardındaki neden, para arzında yapılacak değişimlerin, para talebindeki istikrarsızlıkları arttırabilecek olmasıdır. Post Keynesyenlere göre ana akım iktisatın ulaştığı politika önerisi doğru, ancak arkasındaki neden yanlıştır. Post Keynesyenler paranın kredi yoluyla yaratıldığını ve özel sektörün daima kredi yaratma kapasitesi olduğunu ileri sürmektedir. Ayrıca bu kapasite finansal inovasyonlar yoluyla arttırılabilmektedir. Merkez bankasının para arzında değişikliğe gitmesi durumunda, finansal inovasyon ve

\footnotetext{
${ }^{2}$ Yeni Uzlaşı, para politikalarının tek başına yeterli olmayacağını ileri süren, maliye poltikaların ın da modele eklenmesini öneren, Yeni Neoklasik Sentez'in Post Keynesyen eleştirisine verilen addır (Koç Yurtkur, 2017:813).
} 
deregülasyonlar sayesinde özel sektörün para yaratma esnekliği artacak, böylelikle finansal sistem merkez bankasınca konan para arzı kısıtlarından etkilenmeyecektir. Post Keynesyenler içsel paranın bu yapısal özelliğinden dolayı etkisiz olan para arzı yerine, faizin para politikası aracı olarak kullanılmasını önermektedirler (Palley, 2006:243-246).

Her iki görüşte de paranın içsel kabul edilmesi ve faiz oranlarının dışsal bir değişken olması, Post Keynesyenler ile yeni uzlaşının para teorilerinin oldukça benzer olduğu izlenimi yaratmaktadır. Ancak bu benzerlikler yüzeyseldir ve ayrıntılarda bu iki görüş birbirinden ayrılmaktadır. Post Keynesyenlere göre faiz politikaları piyasa koşullarına bağımlı olmaksızın, merkez bankalarınca belirlenmektedir. Öte yandan yeni uzlaşıya göre, faiz oranları dışsal olsa da, Taylor kuralı piyasa güçleriyle ilişkilendirerek para politikasını içsel hale getirmektedir. Post Keynesyenler için para doğal olarak içseldir. Merkez bankalarının görevi ise geniş çaplı krizlerden kaçınmak için gerekli likiditeyi sağlamaktır. Yeni uzlaşı modelinde ise, merkez bankaları para talebinin istikrarsılı̆ı̆ı nedeniyle para stoğunu kontrol etmede zorlandığı durumlarda, paranın içsel olmasına izin verilmektedir. Bu iki görüş doğal faiz oranı konusunda da birbirinden ayrılmaktadır. Yeni uzlaşı merkez bankası tarafından belirlenen doğal faiz oranı fikrini desteklerken, Post Keynesyen içsel para teorisi, doğal faiz oranını ve dolayısıyla faiz oranıyla ile çıktı arasındaki ilişkiyi reddetmektedir (Rochon \& Setterfield, 2007:19-20)

\section{JOAN ROBINSON VE İÇSEL PARA}

Joan Robinson, her ne kadar Post Keynesyenler arasında parasal konulardaki görüşleri ile öne çıkarılmasa da, erken dönemden itibaren bu konuya katkı sağlayan isimlerden biri olmuştur. 1938 tarihli makalesinde, para tutma isteğinde oluşacak bir artışın, kişilerin ellerinde tuttukları para miktarını arttıracağını, bunun ise para arzında oluşacak bir artış sayesinde gerçekleşebileceğini söylemektedir. Para miktarındaki artışın faizlerde düşüşe yol açacağı, bunun da yatırımları, gelirleri ve ticari aktiviteleri arttıracağını öngören Robinson, bu bağlamda para tutma isteğinin kişilerin inisiyatifi ile değil, bankacılık sisteminin eylemleri sonucunda ortaya çıktığını ileri sürmektedir (Robinson, 1978:29-33). İçsel para teorisinin ortaya koyduğu şekilde olmasa da, bankaların para yaratım sürecinde bir payı olduğunu kavrayan Robinson, Keynes’i likidite tercihi teorisi üzerinden eleştirerek uyumcu yaklaşıma yakın bir tavır sergilemektedir.

İlk kez 1937'de yayınlanan "Introduction to the Theory of Employment" adlı eserinde Robinson, para arzının yasal ve geleneksel kurallar çerçevesinde bankacılık sistemi tarafindan belirlendiğini söylemektedir. Para arzının en önemli parçasının mevduatlar ve bankacılık işlemleri üzerinden kontrol edilen para miktarı olduğuna vurgu yapmaktadır. Robinson'a göre, bankaların ellerinde gereksiz nakit tutmak istemezler, ancak belirli bir nakit oranının da üstüne çıkmayı göze alamazlar. Bankalar arasındaki bu belli bir nakit oranını koruma geleneği, merkez bankasına mevduatları kontrol edebilme gücünü vermektedir. Merkez bankası mevduat miktarını arttırmak istediğinde, açık piyasa işlemleriyle tahvil satın almaktadır, ya da tersi durumda tahvil satarak mevduat miktarını azaltabilmektedir (Robinson, 1969:57-60). Altın standardının geçerli olduğu bir dönemde yazılmış bir eserden para arzıyla ilgili yenilikçi fikirler beklemek haksızlık olacaktır. Ancak bu eserde de Robinson'un bankacılık sisteminin para arzı için ne denli önemli olduğunu kavradığını görebilmekteyiz.

Erken dönem eserlerinde her ne kadar parayla ilgili konulara yer verse de, bu dönemki görüşleri içsel para yaklaşımına uzaktır. Rochon bu konuyla ilgili olarak, Robinson'un görüşlerini 1956 tarihli ünlü kitab1 "The Accumulation of Capital" dan önce ve sonra olarak ayırmak gerektiğini söylemektedir. $\mathrm{Bu}$ tarihten önceki görüşleri genellikle hakim söylemin dışına çıkmamakta ve çoğunlukla Keynes'in likidite tercihi teorisini odağına almaktadır. Bu dönemki görüşleri genel olarak dışsal para yaklaşımıyla uyum içindedir (Rochon, 2005:269).

The Accumulation of Capital, Robinson'un başyapıtı sayılmaktadır ve Post Keynesyen literatüre etki eden eserlerin başında gelmektedir. Robinson bu eserinde para ve finansa özel bir bölüm ayırmış ve kurduğu modelde, bankaların sistemin parasal ihtiyaçlarını karşılayan tedarikçiler olduğunu en baştan belirtmiştir (Robinson, 1956:225). Bankaların olmadığı bir durumda, para temin etmenin çok 
zor olacağına, mübadele aracı olarak kullanılacak araçların, bankaların sağladığı para kadar kullanışlı olmayacağına vurgu yapmıştır (Robinson, 1956:236).

Robinson'un modeline göre, dolaşımdaki para, bankalar tarafindan girişimcilere verilen krediler sonucunda oluşmaktadır. Girişimciler elde ettikleri bu parayı işçilerin ücretlerini ödemekte kullanmaktadırlar. Bankaların çıkardıkları bonolar para yerine geçip, ödemelerde kullanılabildikleri için girişimciler bankalara faiz ödemektedir. Para stokunun büyüklüğü, girişimcilerin ödeyecekleri haftalık ücret toplamına göre değişmektedir (Robinson, 1956:226). Bu görüşlerde içsel para teorisine dair izler açıkça görülmektedir. Robinson, para arzının banka kredilerince oluştuğunu ve miktarının kredi talebince belirleneceğini söyleyerek içsel paranın temel önermelerine uyumlu bir model kurduğunu göstermektedir.

Robinson'un kurduğu modelde, bankacılık sektörü para üretmek ve firmalara kredi sağlamakla yükümlüdür. Tanım gereği tüm ödemeler parayla yapıldığından, firmalar üretim yapabilmek için bankalardan kredi almalıdır. Firmalar, mal üretmekle mükelleftir. Firmalar, bankalardan kredi alır, parasal ücret ödeyerek istihdam satın alır ve ücretli çalışanlara tüketim malları satarlar. Hane halkı ise ücret karşılığı emeğini satışa çıkarmaktadır. Kazandığı ücreti ise mallara ve menkul kıymet alımına harcamaktadır. Böylesi bir ekonomide, kredi, işgücü, tüketim malları ve finans piyasası olmak üzere dört piyasa vardır (Graziani, 1989:617). Birçok yazar, Robinson'un bu modelde ortaya koyduklarıyla, paranın dolaşım teorisi arasında benzerlikler olduğuna dikkat çekmektedir.

Bir girişimci yakın gelecekte gerçekleşecek ödemeleri için paraya ihtiyaç duyduğunda, senet reeskont ettirerek gerekli parayı temin edebilir. Eğer ihtiyacının üzerinde para eline geçerse bunu ödenmemiş borçlarını karşılamak için kullanacaktır. Bonolar daha sonra bankalara geri dönecek, dolanımdaki bono miktarı, ihtiyaçlar ölçüsünde devamlı artacaktır. Örneğin; istihdamdaki ya da parasal ücretlerdeki artış, girişimcilerin bankalara olan borçluluğunu arttıracaktır (Robinson, 1956:227). Lavoie'e göre, Robinson da Kaldor gibi para arzının herhangi bir sınırı olmadığını düşünmektedir. Lavoie, Robinson'un modelinde, M1 para stokunu sadece banka bonolarının oluşturduğunu, çekle yapılan işlemler ve elde tutulan bonoların dahil edilmediğini aktarmaktadır. Ayrıca bu görüşlerin Kaldor'un geri akış mekanizması ile uyumlu olduğunu belirtmektedir (Lavoie, 1999:110).

Rochon, Robinson'un finansal inovasyon kavramını da modeline kattı̆̆ını ileri sürmektedir. Ancak burada inovasyonu yapan Misnky ve onu izleyen yapısalcılarda olduğu gibi bankalar değil firmalardır. Firmaların, yüksek faiz oranlarından kaçınmak için firmalar arası kredi gibi yeni yöntemlere başvurabileceğini öne sürmektedir (Rochon, 2001a:301).

Robinson para arzı için bir arz eğrisi tanımlamamıştır. Bankalar için para arz etmenin marjinal maliyeti yoktur, ancak kredi haline gelmediği sürece getirisi de yoktur. Altın standardının geçerli olduğu durumda para arzı, maden çıkarma ve para basma faaliyetlerinin maliyetine göre belirlenmektedir. Senyorajla da piyasadaki değeri belirlenmektedir. Eğer maden çıkarma ve para basma maliyetleri sabitse arz eğrisi yatay olacaktır. Robinson'a göre para uzun dönemde dahi içseldir (Nell, 2005:297).

Robinson'a göre para, hem stok hem de akım değişkendir. Akım değişken olarak ele alınması paranın yaratım sürecini tanımlamaya yararken, stok değişken olarak ele alındığında, hane halklarının ellerinde tuttukları tasarruflarını nasıl kullanacaklarını açıklamaktadır. Bu nedenle Robinson, paranın fonksiyonlarını yatırım aracı ve mübadele aracı olarak ayırmaktadır (Rochon, 2005:270).

Robinson'un modeline göre, ellerinde bono tutanların, bunu gelecekteki yatırımları finanse etmek için yapmaktadır. Bono fiyatlarının sabit olduğu bir durumda, getirecekleri faiz kazanç olarak görülecektir, ancak bono fiyatları birçok nedene bağlı olarak değişkenlik göstermektedir. Yakın gelecekte gerçekleşecek yatırımını, önceki tasarruflarıyla finanse etmek isteyen girişimci, bonoların faiz oranı, onları satacağı güne kadar gerçekleşebilecek fiyat düşüşünü telafi edecek düzeyde değilse, bahsi geçen bonoları elinde tutma eğiliminde olmayacaktır. Girişimcilerin ellerinde bono tutmaya olan isteksizlikleri, bankalar tarafindan kullanılır ve elde tutulmayan para banka mevduatı haline getirilir. Bankalar bu durumdan avantaj sağlamaya çalışır ve bono satın almaya devam ederek, mevduat 
stoklarını genişletirler (Robinson, 1956:231-234). Bu durum Keynes tarafından da dile getirilmiş, daha sonraları banka-istifçiliği adı altında kavramlaştırılmıştır (Özgür, 2008:67).

Robinson'a göre, bankalar dolaşımdaki para miktarını direkt bir şekilde kontrol edememektedir. Eğer piyasaya talep edilenin üzerinde para sürerlerse, bu fazlalık kendilerine mevduat olarak geri dönecektir. Öte yandan faiz oranlarının, sermaye birikim oranı ve bu yolla işlem hacmi üzerinde etkisi vardır. Yani bankalar faizler üzerindeki etkisini kullanarak dolaylı olarak dolaşımdaki para miktarını etkileyebilirler (Robinson, 1956:234). Robinson'a göre faiz oranları ne enflasyonu arttıracak derecede sermaye birikimine izin verecek kadar düşük, ne de yatırımların önüne geçecek ölçüde yüksek olmalidır (Robinson, 1956:238).

Bankaların, para arzı ve faizlerin belirlenmesi olmak üzere iki önemli fonksiyonu vardır. Merkez bankalarını modelinde öne çıkarmadığından Robinson, dışsal bir temel faiz oranından bahsetmemektedir. Ancak krediler için belirlenen faiz oranlarının nasıl ortaya çıktığını açıklamaktadır. Ona göre faiz oranı, bankanın işlem maliyetlerinin meydana getirdiği artışla belirlenmektedir. Rochon, bu görüşün kendisinin de dahil olduğu pek çok Post Keynesyen iktisatçının görüş̧leriyle uyumlu olduğunu vurgulamaktadır (Rochon, 2001a:301). Kurduğu bu modelde dışsal bir faiz oranına yer vermemiş olsa da Robinson, 1970 tarihinde yayınladığı makalesinde, sabit bir faiz oranı ve tam elastik bir para arzı ile model kurmanın işleri kolaylaştıracağını söyleyerek, yataycı görüşü tam anlamıyla kabullendiğini göstermiştir (Robinson, 1970:507).

\section{SONUÇ}

Joan Robinson'un para ve finans alanlarında yaptığı katkılar, üzerinde uzlaşı sağlanmış bir konu değildir Graziani, Robinson'un çalışmalarında, finansın doğasını ve işleyişindeki sorunları net bir şekilde algıladığının kanıtları olduğunu söylemektedir (Graziani, 1989:616). Rochon ise, Robinson'un "The Accumulation of Capital" ile mevcut parasal anlayışa alternatif olarak heterodoks bir parasal yaklaşım ortaya koyduğuna vurgu yapmaktadır. Ona göre Robinson, Kaldor'dan on dört sene önce ortaya koyduğu görüşleriyle, Post Keynesyen içsel para teorisinin kurucusu kabul edilmelidir (Rochon, 2005:268).

Karşıt görüşe sahip yazarlar ise (Dillard, 1989; Parguez, 2005), Robinson'un parayla ilgili bazı ilginç görüşleri olduğunu, ancak bunları geliştirme konusunda yetersiz kaldığını ileri sürmektedir. Robinson, Keynes'in teorilerini uzun döneme taşıma iddiasında olmasına rağmen, Keynesyen teorinin önemli bir parçası olan paraya yeterince yer vermediği yönünde eleştirilmektedir. Lavoie ise, Robinson'un paraya dair görüşlerinin yenilikçi olmadığı yönünde eleştiri getirmiştir (Lavoie, 1991:265).

$\mathrm{Bu}$ eleştiriler abartılı gibi görünse de, Robinson'un "The Accumulation of Capital" sonrası, burada ortaya koyduğu parasal görüşleri geliştirmediği yadsınamaz bir gerçektir. Ancak bahsi geçen bu eserinde, içsel para teorisinin özünü oluşturan bazı kavramlara yer vermiş ve kendinden sonra gelen iktisatçılara bu teorinin gelişiminde ilham vermiş olması muhtemel gözüken Joan Robinson'un görüşleri göz ardı edilmemelidir.

\section{KAYNAKÇA}

ARESTIS, P. ve HOWELLS, P. (1996). Theoretical Reflections on Endogenous Money: The Problem with Convenience Lending, Cambridge Journal of Economics, 20: 539-551.

ARESTIS, P. Ve SAWYER, M. (2006). The Nature and Role of Monetary Policy When Money is Endogenous, Cambridge Journal of Economics, 30: 847-860

CHICK, V.ve DOW, S. (2002). Monetary Policy with Endogenous Money and Liquidty Preference: A Nondualistic Treatment, Journal of Post Keynesian Economics, 24(4): 587-607. 
DILLARD, D. (1989). "The paradox of money in the economics of Joan Robinson", (Ed.)Feiwel, G. R., The Economics of Imperfect Competition and Employment: Joan Robinson and Beyond, Macmillan, London

DOW, S. (2006). Endogenous Money: Structuralist, P. Arestis \& M. Sawyer (Eds) A Handbook of Alternative Monetary Economics, Edward Elgar

FONTANA, G. (2011). "Bringing Together the Horizontalist and Structuralist Analyses of Endogenous Money", (Ed.) Arestis, P., Microeconomics, Macroecenomics and Economic Policy, Palgrave Macmillan

FONTANA, G. (2003). Post Keynasian Approaches to Endogenous Money: A Time Framework Explanation, Review of Political Economy, 15(3): 291-314,

FONTANA, G. Ve PALACIO-VERA, A. (2003). Is There an Active Role for Monetary Policy in the Endogenous Money, Journal of Economic Issues, 37(2), 511-517

FOSTER, G. P. (1986). The Endogeneity of Money and Keynes's General Theory, Journal of Economic Issues, 20(4): 953-968

GNOS, G. ve ROCHON, L.P. (2003). Joan Robinson and Keynes: Finance, Relative Prices and the Monetary Circuit, Review of Political Economy, 15(4): 483-491

GRAZIANI, A. (1989). "Money and Finance in Joan Robinson's Works", (Ed.) Feiwel, G. R., The Economics of Imperfect Competition and Employment: Joan Robinson and Beyond, Macmillan, London

KALDOR, N. (1970). The New Monetarism, Lloyds Bank Review, July, 1-17

KALDOR, N. (1960). The Radcliffe Report, The Review of Economics and Statistics, 42(1): 14-19

KOÇ YURTKUR, A. (2017). Para ve Maliye Politikalarının Etkileşimi Meselesi: Yeni Uzlaşı, Uluslararası Yönetim İktisat ve İşletme Dergisi, ICMEB17 Özel Sayıs1

LAVOIE, M. (2006a). Introduction to Post-Keynesian Economics, Palgrave Macmillan, New York

LAVOIE, M. (2006b). "Endogenous Money: Accommodationist”, (Ed.) Arestis, P ve Sawyer , M.,

A Handbook of Alternative Monetary Economics, Edward Elgar

LAVOIE, M. (1999). The Credit-led Supply of Deposits and the Demand for Money: Kaldor's Reflux Mechanism as Previously Endorsed by Joan Robinson, Cambridge Journal of Economics, 23(1): 103-113

LAVOIE, M. (1996). Horizontalism, Structuralism, Liquidity Preference and the Principle of Increasing Risk, Scottish Journal of Political Economy, 43(3): 275-300

LAVOIE, M. (1991). "Change, Continuity and Originality in Kaldor's Monetary Theory", (Ed.) Nell, E. ve Semmler, W., Nicholas Kaldor and Mainstream Economics: Confrontation or Convergences?, St. Martin's Press, New York

MINSKY, H. (1957a). Central Banking and Money Market Changes, The Quarterly Journal of Economics, 71(2): 171-187

MINSKY, H. (1957b). Monetary Systems and Accelerator Models, The American Economic Review, 47(6): 859-883

MOORE, B J. (1998). Accommodation to Accommodationism: A Note, Journal of Post Keynesian Economics, 21(1): 175-178

MOORE, B. J. (1991a). "Marx, Keynes, Kalecki and Kaldor on the Rate of Interest as a Monetary Phenomenon", (Ed.) Nell, E. ve Semmler, W., Nicholas Kaldor and Mainstream Economics: Confrontation or Convergences?, St. Martin's Press, New York 
MOORE, B. J. (1991b). Has the Demand for Money Mislaid? A Reply to "Has Moore Become too Horizontal?", Journal of Post Keynesian Economics, 14(1): 125-133

MOORE, B. J. (1988). Horizontalists and Verticalists: The Macroeconomics of Credit Money, Cambridge University Press

MOORE, B. J. (1984). Contemporaneous Reserve Accounting: Can Reserve Be QuantityConstrained?, Journal of Post Keynesian Economics, 7(1): 103-113

NELL, E. J. (2005). "Money in The Accumulation of Capital”, (Ed.) Gibson, B., Joan Robinson's Economics, Edward Elgar

ÖZGÜR, G. (2008). İçsel Para Teorisine Genel Bir Bakış, Hacettepe Üniversitesi İktisadi ve İdari Bilimler Fakültesi Dergisi, 26(2): 51-79

PALLEY, T. I. (2006). "Monetary Policy in an Endogenous Money Economy", (Eds.) Arestis, P., Sawyer, M., A Handbook of Alternative Monetary Economics, Edward Elgar, Cheltenham

PALLEY, T. I. (1996). Accommodationism versus Structuralism: Time for an Accommodation, Journal of Post Keynesian Economics, 18(4): 585-594

PARGUEZ, A. (2005). "An Inquiry into a Dark Mystery in the History of the Monetary Theory of Production: What Went Wrong with the Early Contribution of Joan Robinson", (Ed.) Fontana G. ve Realfonzo R., The Monetary Theory of Production. Palgrave Macmillan, London

POLLIN, R. (1991). Two Theories of Money Supply Endogeneity: Some Empirical Evidence, Journal of Post Keynasian Economics, 13(3): 366-396

ROBINSON, J. (1978). Contributions to Modern Economics, Academic Press

ROBINSON, J. (1970). Quantity Theories Old and New: Comment, Journal of Money, Credit and Banking, 2(4): 504-512

ROBINSON, J. (1969). Introduction to the Theory of Employment, Palgrave Macmillan, London

ROBINSON, J. (1956). The Accumulation of Capital, Richard D. Irwin, Illinois

ROCHON, L.P. ve SETTERFIELD, M. (2007). Interest Rates, Income Distribution and Monetary Policy Dominance: Post Keynesians and the "Fair Rate" of Interest, Journal of Post Keynesian Economics, 30:1, 13-42

ROCHON, L. P. (2005). "Robinson on Credit, Money and Finance", (Ed.) Gibson, B., Joan Robinson's Economics, Edward Elgar

ROCHON, L.P. (2001a). Cambridge's Contribution to Endogenous Money: Robinson and Kahn on Credit and Money, Review of Political Economy, 13(3): 287-307

ROCHON, L. P. (2001b). "Horizontalism: Setting the Record Straight", (Ed. Rochon, L. P. Ve Vernengo, M., Credit, Interest Rates and the Open Economy, Edward Elgar

VERNENGO, M. ve ROCHON, L.P. (2001). Kaldor and Robinson on Money and Growth, European Journal of the History of Economic Thought, 8(1) 75-103

WRAY, L.R. (1990). Money and Credit in Capitalist Economies: The Endogenous Money Approach, Edward Elgar 